\title{
Study on the effects of partial cooling for physiological responses relief in duty booth under high temperature weather

\author{
Zhihao $\mathrm{Li}^{1,}$ a , Bing Wei ${ }^{1, \mathrm{~b}}$, and Guozhong Zheng ${ }^{1, \mathrm{c},{ }^{*}}$ \\ ${ }^{1}$ Department of Power Engineering, North China Electric Power University, Baoding, China \\ aemail:Izhgiz@163.com, bemail:weibing8899@sina.com, cemail:ansystem@126.com \\ ${ }^{*}$ Corresponding author
}

\begin{abstract}
Key words: Outdoor high temperature, Closed environment, Physiological responses, Partial cooling

Abstract: High temperature and hot sun environments are prevalent in many situations. The extreme environments have put forward a severe challenge to the health and safety of the outdoor workers. However, people in duty booth still stick to their post to guarantee social normal production and living activities. In this paper, security guards and tower crane workers are selected as research objects. In order to study the effects of partial cooling, the physiological responses in three conditions including head cooling, limbs cooling and no cooling are compared. The research shows that limbs cooling and head cooling can reduce the body's skin temperature, then relieve the sweat rate and improve the body's thermal sensation. The results of the study can provide an important method foundation for the protection of the worker's heath under the outdoor high temperature and sun exposure environment.
\end{abstract}

\section{Introduction}

In the background of global warming, the extremely high temperature weather appears frequently. The hot environment directly influences people's daily life and social production. Different degrees of heat stress, such as heat stroke and dehydration, are produced when people work and live in high temperature environment. Besides, high temperature environment will also results in productivity decrease and safety problems [1]. The security men and tower crane workers still stick to their post to guarantee social normal production and living activities under the extreme environment. The high temperature in closed environment presents a severe challenge to the health and safety of the workers.

At present, there have been some research achievements in the fields of physiological responses in outdoor hot environment. The objects of the researches were mainly concentrated on soldiers [24], athletes [5], construction workers [6-8] and farmers [7, 8]. However, the research on some social livelihood posts, such as the security men and tower crane workers, is basically in blank. In addition, the current research contents are focused on the physiological response in common outdoor hot environment, but the studies on physiological responses relief mechanism in the outdoor closed environment are also sparse.

The security men and tower crane workers are selected as the research objects in this paper. Different relief measures for security men and tower crane workers are selected, including the head cooling and limbs cooling. The effects of the relief measures are studied by comparing the physiological responses under the condition of no relief measure and the condition of relief measure. The results of the study can provide an important method foundation for the analysis of the relief measures and the protection of the worker's heath under the outdoor high temperature and sun exposure environment.

\section{Experiment and methodology}

Experimental condition. The experiments were conducted in an open area of North China Electric Power University. 
The outdoor tent was used to simulate a duty booth. The closed environment of the outdoor tent is similar to the environment of duty booth. The material of the outdoor tent is polyester fabric. And the size is $120 \times 120 \times 190 \mathrm{~cm}$.

The experiments were conducted in sunny days in summer. The experiment conditions are as follow: (1) Head cooling: the samples sat in the outdoor tent with the ambient temperature water to cool head. (2) Limbs cooling: the samples sat in the outdoor tent with the ambient temperature water to cool limbs. (3) No cooling: the samples only sat in the outdoor tent. The working time of each group was 60 minutes. The environmental parameters, physiological parameters and thermal sensation were measured every 15 minutes. For condition (1) and (2), the subjects were cooled by the ambient temperature water every 15 minutes and the water consumption of per cooling was about $250 \mathrm{~g}$. There were 10 subjects in each group of experiment condition.

Experimental apparatus. The environmental parameters included dry bulb temperature, solar radiation intensity and relative humidity. Physiological parameters included heart rate, rectal temperature, skin temperature, body weight, blood pressure and grip strength. Instruments used in the measurement are shown in Table 1. The skin temperature is the weighted mean temperature of the chest temperature, the upper arm temperature, the thigh temperature and the leg temperature. The weighted coefficients are 0.3, 0.3, 0.2 and 0.2, individually [9].

The thermal sensation is scored according to the subjective thermal sensation of the subjects, and the specific score is shown in Table 2 [10].

Table 1 Measurement parameters and measuring instruments

\begin{tabular}{|c|c|c|c|}
\hline Parameter & Instrument & Model & Precision \\
\hline Dry bulb temperature & Thermal index meter & AZ8778 & $\pm 0.6\left[{ }^{\circ} \mathrm{C}\right]$ \\
\hline Solar radiation intensity & Solar power meter & SM-206 & $\pm 10\left[\mathrm{~W} / \mathrm{m}^{2}\right]$ \\
\hline Relative humidity & Thermal index meter & AZ8778 & $\pm 3 \%$ \\
\hline Heart rate & Electronic sphygmomanometer & OMRON HEM-7051 & $\pm 5 \%$ \\
\hline Rectal temperature & Electronic thermometer & OMRON MC-347 & $\pm 0.1[\square]$ \\
\hline Skin temperature & $\begin{array}{l}\text { Infrared temperature } \\
\text { instrument }\end{array}$ & DT806 & $\pm 0.3[\square]$ \\
\hline Blood pressure & Electronic sphygmomanometer & OMRON HEM-7051 & $\pm 4[\mathrm{mmHg}]$ \\
\hline Body weight & Electronic weight meter & $\begin{array}{l}\text { Yousheng } \\
\text { XH3100system }\end{array}$ & $\pm 15[\mathrm{~g}]$ \\
\hline Grip strength & Electronic dynamometer & CAMRY EH101 & $\pm 0.5[\mathrm{~kg}]$ \\
\hline
\end{tabular}

Table 2 Thermal sensation evaluation table

\begin{tabular}{lllllllll}
\hline Very cold & Cold & Cool & Slightly cool & Neutral & Slightly warm & Warm & Hot & Very hot \\
\hline-4 & -3 & -2 & -1 & 0 & 1 & 2 & 3 & 4
\end{tabular}

Experimental sample. College students and gradute students were selected as the experimental samples. The subjects were required to be healthy and have no disease history. Before the experiment, the subjects were tested for basic physiological parameters (heart rate and blood pressure). In according with the inclusion and exclusion's criteria (the heart rate should be less than 100 beats/min, and the blood pressure should be less than 140/90 $\mathrm{mmHg}$ ), the subjects who volunteered to participate were seriously selected.

Environmental parameters. The dry bulb temperature and relative humidity in the tents, and the solar radiation intensity outside the tents are shown in Table 3. The whole parameters in Table 3 are the average values of each group.

Table 3 Environmental parameters

\begin{tabular}{llll}
\hline Condition & $\begin{array}{l}\text { Dry bulb temperature } \\
{[\square]}\end{array}$ & $\begin{array}{l}\text { Relative humidity } \\
{[\%]}\end{array}$ & $\begin{array}{l}\text { Solar radiation intensity } \\
{\left[\mathrm{W} / \mathrm{m}^{2}\right]}\end{array}$ \\
\hline Head cooling & 40.1 & 59.6 & 618 \\
Limbs cooling & 42.1 & 58.1 & 660 \\
No cooling & 42.1 & 42.8 & 872 \\
\hline
\end{tabular}




\section{Results}

Heart rate. Fig. 1 shows the variation of the heart rate in the three different conditions. As shown in Fig. 1, the three curves present a rising trend in the whole process. In the head cooling condition, the heart rate rises in the first 45 minutes, then it is almost unchanged and the value at 60th min is 106.4 beats/min. In the limbs cooling condition, the heart rate rises in the first 30 minutes, then it decreases in small fluctuation and the value at 60th $\mathrm{min}$ is 101.7 beats/min. In the no cooling condition, the heart rate increases from 87.1 beats/min to 104.4 beats/min. Compared with the initial values, the final values increase by 25.6 beats/min, 14.3 beats/min and 23.0 beats $/ \mathrm{min}$, respectively. From these curves, it can be concluded that, compared with no relief measures, the relief effects of head cooling and limbs cooling on heart rate are not obvious, and cooling measures even aggravate the burden of heart. The relative humidity in the closed environment increases after cooling. The data shows that the average relative humidity of no relief measures is $42.8 \%$, but the average relative humidity of head cooling and limbs cooling are $59.6 \%$ and $58.1 \%$, respectively.

Blood pressure. Fig. 2 shows the variation of systolic pressure in the conditions of head cooling, limbs cooling and no cooling. In the head cooling condition, the systolic pressure increases from $116.2 \mathrm{mmHg}$ to $121.4 \mathrm{mmHg}$ at 15 th $\mathrm{min}$. Subsequently it drops to $115.6 \mathrm{mmHg}$ at $30 \mathrm{th} \mathrm{min}$, and then it rises to $118.9 \mathrm{mmHg}$ at 60th $\mathrm{min}$. In the limbs cooling condition, the systolic pressure increases from $118.0 \mathrm{mmHg}$ to $120.0 \mathrm{mmHg}$ at 15 th $\mathrm{min}$, and then it slowly decrease. At 60th $\mathrm{min}$ it is $116.6 \mathrm{mmHg}$. In the no cooling condition, the systolic pressure fluctuates slightly in a range of $113.9 \mathrm{mmHg}$ to $117.1 \mathrm{mmHg}$ during the whole process and these values are within the normal range. Cooling measures can make the systolic pressure elevate because the skin is directly stimulated by the water thus the vessel of cooling parts stress shrinkage. It is known that the three curves are in normal range, thus head cooling and limbs cooling have no relief effect on systolic pressure.

Fig. 3 shows the variation of diastolic pressure in the conditions of head cooling, limbs cooling and no cooling. As shown in Fig 3, the changing trends of the three curves are approximately the same. The initial values of the head cooling, limbs cooling and no cooling conditions are 66.5 $\mathrm{mmHg}, 62.7 \mathrm{mmHg}$ and $71.3 \mathrm{mmHg}$, respectively. And the diastolic pressure decrease to 58.1 $\mathrm{mmHg}, 54.1 \mathrm{mmHg}$ and $63.8 \mathrm{mmHg}$ at 30th $\mathrm{min}$, respectively. Then they changed slightly. Compared with no relief measure, the head cooling and limbs cooling have no relief effect on diastolic pressure.

Body temperature regulation. In order to analyze the temperature regulation of human body in closed environment under outdoor high temperature, the sweat rate, skin temperature and rectal temperature are selected in this paper.

Sweat rate reflects the ability of human body to remove the extra heat by sweat. The sweat quantity is defined as the weight variation of a naked subject between each measurement, and then the sweat rate is the sweat quantity of human body per unit time. Fig. 4 shows the variation of sweat rate in the conditions of head cooling, limbs cooling and no cooling. As shown in Fig. 4, the changing trends of the three curves all increase. In the limbs cooling condition, the sweat rate decreases slightly in the range of 45 th to 60th min. Compared with the initial values, the final values of the three conditions are $15.813 \mathrm{~g} / \mathrm{min}, 14.617 \mathrm{~g} / \mathrm{min}$ and $19.733 \mathrm{~g} / \mathrm{min}$, respectively. When subjects enter the outdoor tents, the sweat mechanism immediately operates. At this time, the human body mostly or completely relies on sweat to achieve the effect of cooling. Meanwhile, a part of the heat is taken away by the partial cooing. So the sweat rate can be slowly down in a certain extent by the partial cooling. There are close relationships between the sweat rate and the change trend of rectal temperature. 


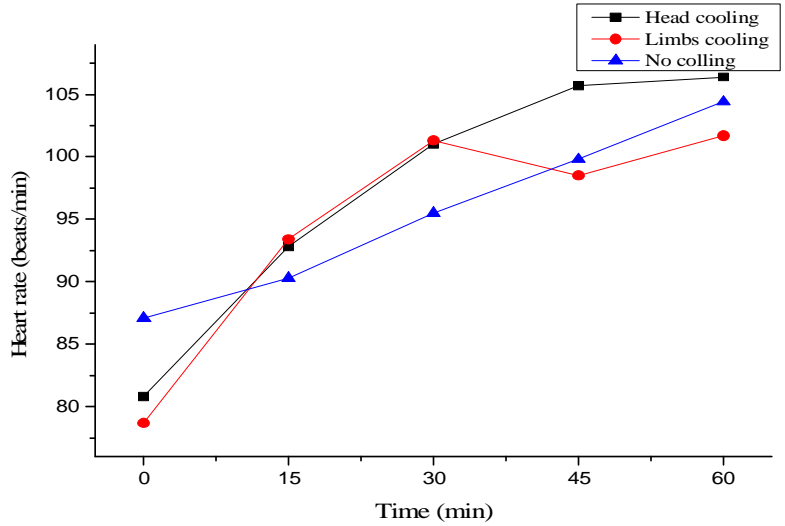

Fig. 1 The variation of heart rate

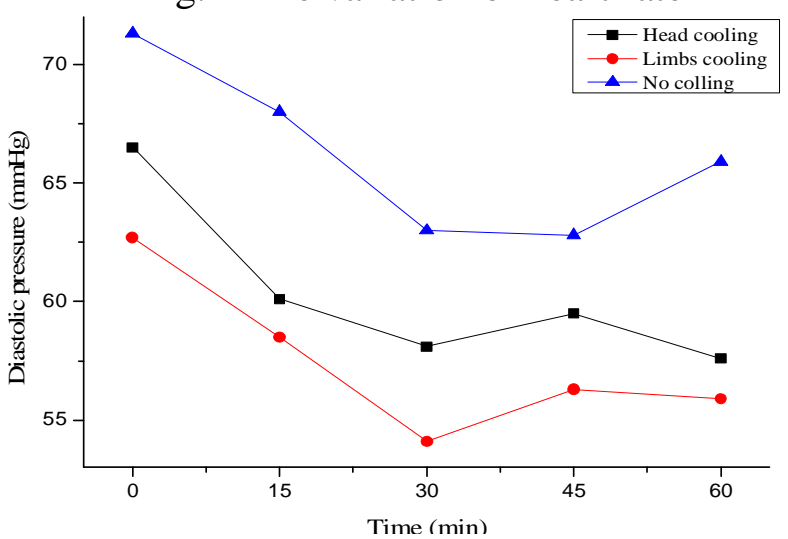

Fig. 3 The variation of diastolic pressure

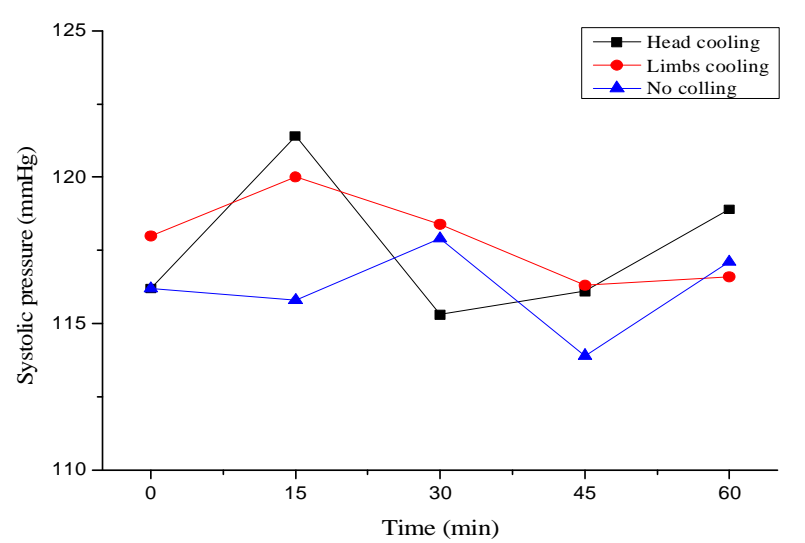

Fig. 2 The variation of systolic pressure

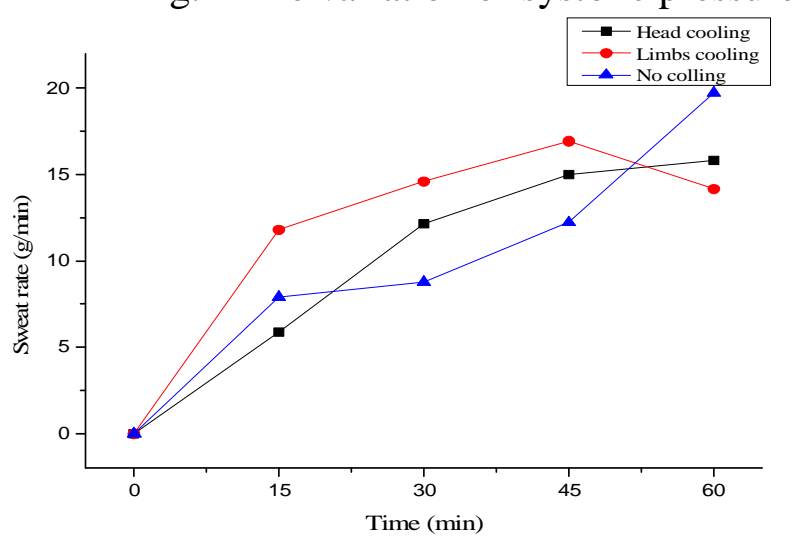

Fig. 4 The variation of sweat rate

Fig. 5 shows the variation of skin temperature in the conditions of head cooling, limbs cooling and no cooling. In the head cooling condition, the skin temperature decreases slightly at 15 th min and then increases. After 30th min it fluctuates slightly. In the limbs cooling condition, the skin temperature is relatively stable throughout the process. In the no cooling condition, the skin temperature increases throughout the process. Compared with the initial values, the final values of the three conditions increase by $0.1 \square, 0.1 \square$ and $0.4 \square$, respectively. The skin temperature changes slowly because skin can be directly cooled by the partial cooling. The fluctuation of sweat rate of no cooling is the maximum in the three conditions. To sum up, the body's heat absorption is larger than the evaporation cooling.

Fig. 6 shows the variation of rectal temperature in the conditions of head cooling, limbs cooling and no cooling. As shown in Fig. 6, the three curves all rise during the whole process. Compared with the initial values, the final values of the three conditions increase by $0.9 \square, 0.9 \square$ and $0.4 \square$, respectively. The rectal temperature in the no cooling condition rises more slowly than the other two curves. The relief effects of the partial cooling for rectal temperature are not optimistic. Human body cannot well rely on the evaporation of sweat to carry away the heat because the relative humidity of the tent is higher after cooling. Heat absorbed by the body from the outside environment is higher than the heat dissipated itself. The surface of the skin is only stimulated by body the partial cooling, but human organs are not affected. From Fig. 4 and Fig. 6, it can be found that the sweat rate and rectal temperature all increase apparently and they influence each other.

Fatigue. In this paper, the grip strength was selected as an indicator of the human body fatigue.

Fig. 7 shows the variation of grip strength in the conditions of head cooling, limbs cooling and no cooling. In the head cooling condition, the grip strength decreases from $40.52 \mathrm{~kg}$ to $37.87 \mathrm{~kg}$ at 45th min, and then it increases sharply. In the limbs cooling condition, the grip strength fluctuates radically during the whole process. In no cooling condition, the grip strength changes slightly throughout the process. It can be concluded that cooling measures are not very useful ways to make people feel more comfort, on the contrary, the increment of humidity may make subjects feel more tired. According to the responses of the subjects, the stuffy environment made them have uncomfortable symptoms, such as nausea and chest tightness. 
Thermal sensation. In this paper, the thermal sensation is used as the subjective evaluation of the closed environment under high temperature and the auxiliary reference of objective index of physiological parameters of human body.

Fig. 8 shows the variation of thermal sensation in the condition of head cooling, limbs cooling and no cooling. In the no cooling condition, the curve increases steeply from 0 th to 15 th $\mathrm{min}$. The thermal sensation increases from 2.9 to 3.7 , the value at 30th min increases by 0.8 . Then it gradually increases. In the head cooling and limbs cooling conditions, the thermal sensation rise from 3.3 and 3.0 to 3.8 and 3.5 , respectively. Compared with the initial values, the final values increase by 0.5 and 0.5 , respectively. The skin temperature was quickly cooled to give human a temporary cool feeling due to the evaporation of the water. In short, the cooling measures have a good effect on thermal sensation.

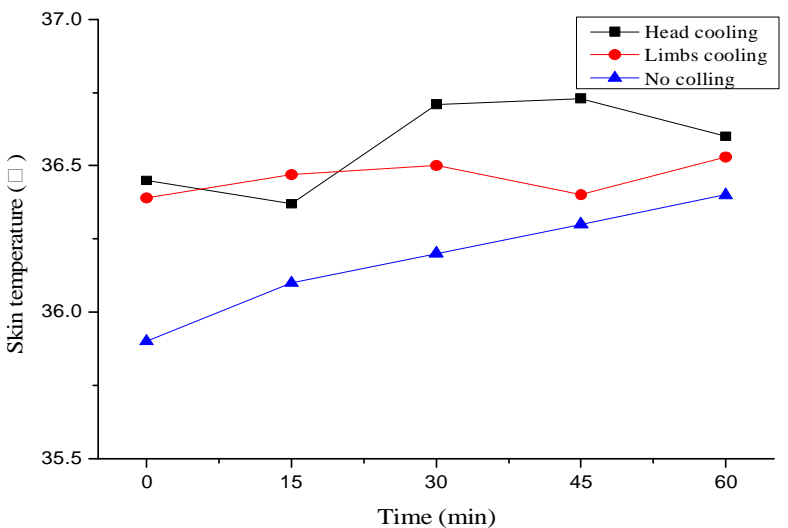

Fig. 5 The variation of skin temperature

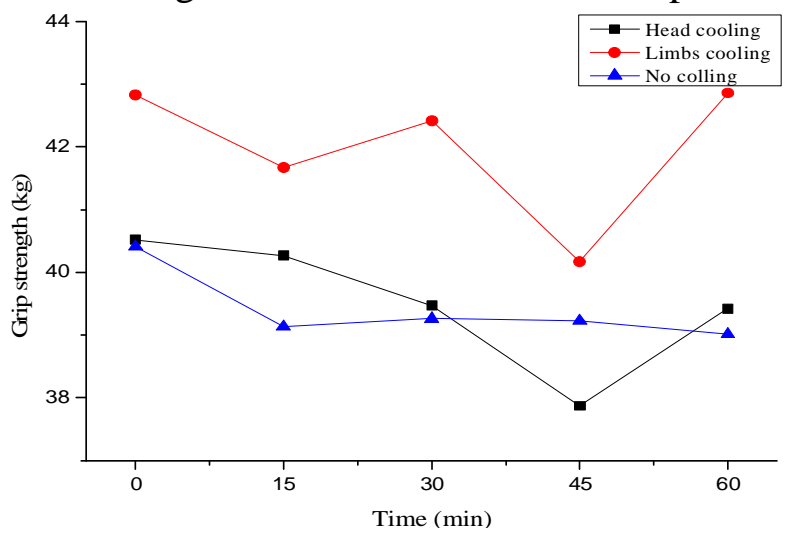

Fig. 7 The variation of grip strength

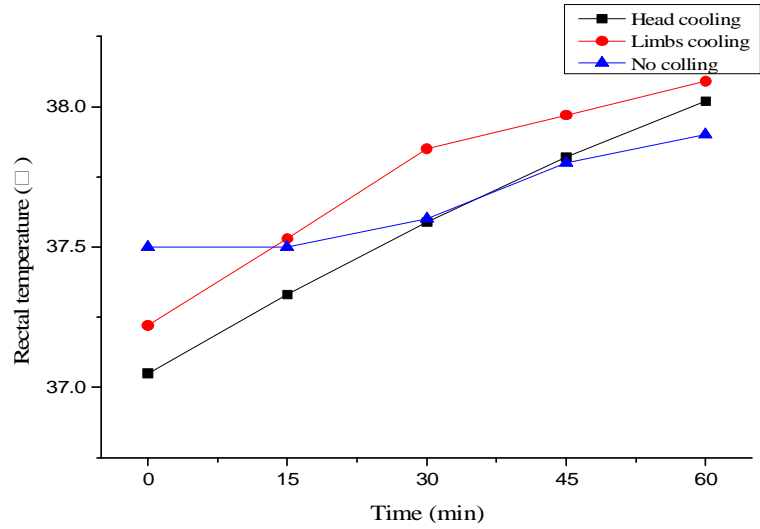

Fig. 6 The variation of rectal temperature

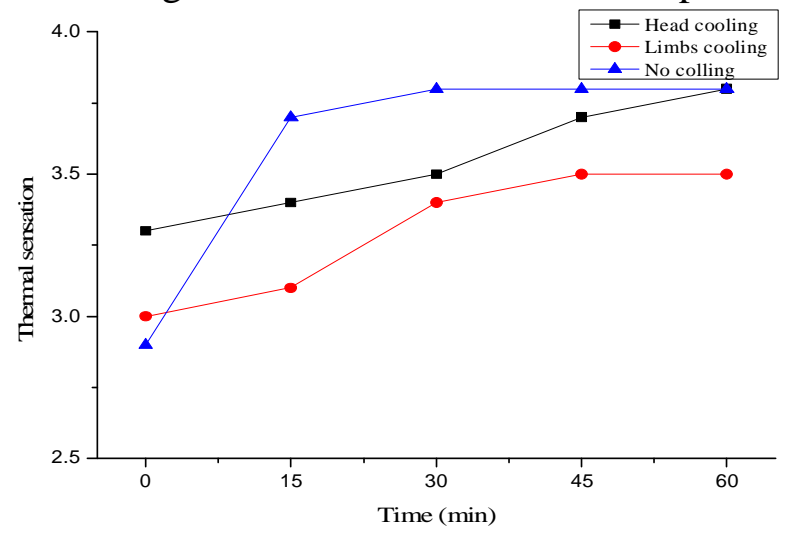

Fig. 8 The variation of thermal sensation

\section{Conclusions}

In order to study the effect of partial cooling for physiological stress, the objective physiological data and subjective evaluation are analyzed for people in closed environment under high temperature.

In the head cooling and limbs cooling conditions, the skin temperature fluctuates slowly and the thermal sensation reduces to a certain extent. The surface of skin is only stimulated by the partial cooling but human organs are not affected. So the relief effects of body partial cooling are not optimistic for the heart rate, blood pressure and rectal temperature. The relative humidity of the outdoor tent is higher after cooling and the cooling measures even increase the feeling of fatigue. The research methods and results of this paper are also applied for soldiers, athletes, farmers and so on.

\section{Acknowledgements}

This research has been supported by the National Natural Science Foundation of China (Grant No. 51408220). The authors would like to acknowledge the subjects who volunteered for this study. 


\section{References}

[1] G. P. Zhang. 2008. Ergonomics and Its Application. China Machine Press, Beijing.

[2] P. Tikuisis, and A. A. Keefe. 2005. "Heat strain at high levels does not degrade target detection and rifle marksmanship," Aviation, Space and Environmental Medicine, 76(10): 963-969.

[3] G. X. Du. 1985. "Physiological upper limit of people working in hot environments," Bulletin of the Academy of Military Medical Sciences, 18(4): 375-379

[4] Z. Z. Lu. 2000. "Study on the tolerance time limit of soldiers working in hot and humid environment," Chinese Journal of Industrial Hygiene and Occupational Diseases, 18(6): 336338.

[5] S. F. Godek, A. R. Bartolozzi, and J. J. Godek. 2005. "Sweat rate and fluid turnover in American football players compared with runners in a hot and humid environment," British Journal of Sports Medicine, 39(4): 205-211.

[6] P. Yoopat, P. T. T. Glinsukon, K. Vanwonterghem, and V. Louhevaara. 2002. "Ergonomics in practice: physical workload and heat stress in Thailand," International Journal of Occupational Safety and Ergonomics, 8(1): 83-93.

[7] S. Bober, G. Charoensiri, D. Harrison, R. Hickcox, C. R. Miller, S. Sa-nguankulchai, and P. Sutthanusorn. March, 2012. "Heat impacts on occupational health a comparison between agricultural and industrial settings in the time of climate change," Final report, BSAC, Thammasat University Faculty of Public Health, and Worcester Polytechnic Institute.

[8] P. K. Nag, A. Nag, and S. P. Ashtekar. 2005. "Thermal limits of men in moderate to heavy work in tropical farming," Industrial Health, 45(1): 107-117.

[9] Z. F. Jin, and Y. X. Ying. 2001. Building environment. China Building Industry Press, Beijing.

[10] International Organization for Standardization. 1995. "ISO 10051 Ergonomics of the thermal environment-assessment of the influence of the thermal environment using subjective judgment scales," International Organization for Standardization, Geneva. 